\title{
Vaginal lactic acid elicits an anti-inflammatory response from human cervicovaginal epithelial cells and inhibits production of pro-inflammatory mediators associated with HIV acquisition
}

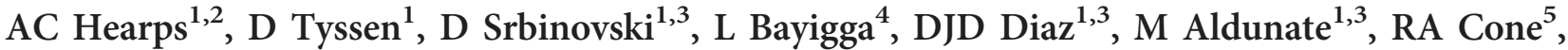 \\ R Gugasyan ${ }^{1,6}$, DJ Anderson ${ }^{4}$ and G Tachedjian ${ }^{1,2,7,8}$
}

Inflammation in the female reproductive tract (FRT) is associated with increased HIV transmission. Lactobacillus spp. dominate the vaginal microbiota of many women and their presence is associated with reduced HIV acquisition. Here we demonstrate that lactic acid (LA), a major organic acid metabolite produced by lactobacilli, mediates anti-inflammatory effects on human cervicovaginal epithelial cells. Treatment of human vaginal and cervical epithelial cell lines with LA (pH 3.9) elicited significant increases in the production of the anti-inflammatory cytokine IL-1RA. When added simultaneously or prior to stimulation, LA inhibited the Toll-like receptor agonist-elicited production of inflammatory mediators IL-6, IL-8, TNF $\alpha$, RANTES, and MIP3 $\alpha$ from epithelial cell lines and prevented IL-6 and IL-8 production by seminal plasma. The anti-inflammatory effect of $L A$ was mediated by the protonated form present at $\mathrm{pH} \leq 3.86$ and was observed with both L- and D-isomers. A similar anti-inflammatory effect of LA was observed in primary cervicovaginal cells and in an organotypic epithelial tissue model. These findings identify a novel property of LA that acts directly on epithelial cells to inhibit FRT inflammation and highlights the potential use of LA-containing agents in the lower FRT as adjuncts to female-initiated strategies to reduce HIV acquisition.

\section{INTRODUCTION}

Curbing the HIV epidemic will require effective methods to reduce HIV acquisition in women, who represent almost half the global HIV burden of 37 million infected individuals ${ }^{1}$ and are eight times more likely than men to acquire HIV following vaginal intercourse. ${ }^{2}$ The female reproductive tract (FRT) contains numerous structural, environmental, and immunological barriers to HIV infection. ${ }^{3}$ However, the importance of the vaginal microbiota and particularly the role of their organic acid metabolites in influencing HIV transmission through immunomodulatory effects on the FRT mucosa remain largely unknown.
The vaginal microbiota of asymptomatic women of reproductive age is generally dominated by Lactobacillus spp. ${ }^{4}$ which is associated with reduced susceptibility to HIV and other sexually transmitted infections (STIs) ${ }^{5,6}$ In contrast, microbial dysbioses such as bacterial vaginosis (BV) are associated with a decreased prevalence of lactobacilli and an increase in highdiversity bacterial communities comprising strict or facultative anaerobes including Gardnerella, Prevotella, and Atopobium (reviewed in Aldunate et al. ${ }^{3}$ ). BV is associated with a more than threefold increased risk of HIV acquisition, ${ }^{7}$ whereas HIV-positive women with BV have elevated HIV viral loads in their cervicovaginal fluids ${ }^{8}$ and a threefold increased risk of

${ }^{1}$ Centre for Biomedical Research, Burnet Institute, Melbourne, Victoria, Australia. ${ }^{2}$ Department of Infectious Diseases, Monash University, Melbourne, Victoria, Australia. ${ }^{3}$ Department of Microbiology, Monash University, Clayton, Victoria, Australia. ${ }^{4}$ Departments of Obstetrics and Gynecology, Microbiology and Medicine, Boston University School of Medicine, Boston, Massachusetts, USA. ${ }^{5}$ Department of Biophysics, Johns Hopkins University, Baltimore, Maryland, USA. ${ }^{6}$ Department of Immunology, Monash University, Melbourne, Victoria, Australia. ${ }^{7}$ Department of Microbiology and Immunology, Peter Doherty Institute for Infection and Immunity, University of Melbourne, Melbourne, Victoria, Australia and ${ }^{8}$ School of Science, College of Science, Engineering and Health, RMIT University, Melbourne, Victoria, Australia. Correspondence: G Tachedjian (gildat@burnet.edu.au) 
transmitting HIV to uninfected male partners. ${ }^{9}$ Studies of the vaginal microbiota of women in Africa have demonstrated that high-diversity bacterial communities lacking Lactobacillus spp., such as those found in BV, are associated with increased levels of pro-inflammatory mediators in the FRT ${ }^{10-13}$ and increased risk of HIV acquisition, ${ }^{14}$ with a recent study reporting a greater than fourfold increased risk of HIV acquisition as compared to women with Lactobacillus crispatus-dominated vaginal microbiota. ${ }^{13}$ STIs including Chlamydia trachomatis, Neisseria gonorrhoeae, and herpes simplex virus type 2 also increase FRT inflammation ${ }^{12}$ and HIV risk, ${ }^{15}$ supporting the critical link between FRT inflammation and HIV transmission (reviewed in Passmore et al. ${ }^{16}$ ).

The mechanism through which inflammation heightens HIV acquisition is likely multifactorial. Pro-inflammatory factors including MIP3 $\alpha$ and IL-8 are associated with increased activation and recruitment of HIV target CD $4+\mathrm{T}$ cells into the genital mucosa and disruption of tight junctions between epithelial cells, ${ }^{10,17}$ facilitating the passage of virions through the epithelial layer. Indeed, women with a high-diversity, low Lactobacillus abundance microbiota have heightened FRT inflammation and a 17 -fold increase in the number of HIV target cells in the FRT as compared to women with a L. crispatus-dominated microbiota. ${ }^{13}$ Stimulation of primary genital epithelial cells with viral and bacterial pathogens elicits TNF $\alpha$, IL-6, and IL- 8 production, which promotes HIV replication in target cells by activating the transcription factor nuclear factor- $\kappa \mathrm{B}(\mathrm{NF}-\kappa \mathrm{B}){ }^{18}$ Vaginal exposure to simian immunodeficiency virus mediates the production of MIP- $3 \alpha$ from endocervical cells that recruits target cells leading to establishment of simian immunodeficiency virus infection in rhesus macaques. ${ }^{19}$ These studies highlight the critical role of the genital epithelium in promoting HIV susceptibility through influencing the inflammatory state of the FRT mucosa.

In addition to providing a physical barrier, cervicovaginal epithelial cells are critical innate immune sentinels that detect and respond to the vaginal microbiota and invading pathogens. FRT epithelial cells possess Toll-like receptor (TLR) pathogen recognition receptors and respond to both commensal bacteria and invading pathogens by producing cytokines and immune mediators. ${ }^{20,21}$ Vaginal dysbioses and low Lactobacillus abundance microbiota are associated with genital inflammation in vivo, ${ }^{10,12,13}$ and in vitro co-culture studies demonstrate that $\mathrm{BV}$-associated bacteria directly elicit pro-inflammatory cytokine production from cervicovaginal epithelial cells and tissue models. ${ }^{10,21-23}$ In contrast, co-culture of FRT epithelial cells with vaginal Lactobacillus spp. or lactobacillus-dominated microbiota is associated with a non- or anti-inflammatory response. ${ }^{10,21-23}$ Furthermore, co-culture of Lactobacillus spp. with vaginal tissue models containing HIV target cells impairs HIV infection. ${ }^{22}$ These findings suggest that modulation of the innate immune response of FRT epithelial cells by vaginal microbiota may play a role in HIV susceptibility.

Short-chain fatty acids are metabolites produced by microbiota that dampen mucosal inflammation of gut mucosa, although little is known about the role of organic acid metabolites on the FRT mucosa. The vagina of women with lactobacillus-dominated microbiota is acidified to $\mathrm{pH}<4.0$ by $1 \%$ lactic acid (LA), the major organic acid metabolite produced by Lactobacillus spp., that inactivates BV-associated bacteria and has potent HIV virucidal activity. ${ }^{24,25}$ In contrast, BV is associated with an increase in $\mathrm{pH}>4.5$ and a sharp decrease in LA in the lower FRT (reviewed in Aldunate et al. ${ }^{3}$ ). Here we investigated whether LA is a mediator of the immunomodulatory effects observed with Lactobacillus spp. on cervicovaginal epithelial cells and determined its role in decreasing inflammation elicited by viral and bacterial pathogen-associated molecular patterns and seminal plasma.

\section{RESULTS}

\section{Cervicovaginal epithelial cells cultured in transwells remain viable in the presence of physiological concentrations of LA}

The average physiological LA concentration in the vaginal lumen of women with lactobacillus-dominated microbiota is $1.0 \pm 0.2 \%(\mathrm{w} / \mathrm{v})$ and the vaginal $\mathrm{pH}$ ranges from 2.8 to $4.2{ }^{26}$ However, the presence of mucus and the stratified structure of the vaginal epithelium, that includes surface layers of flattened dead cells, ${ }^{27}$ means that viable cells within the basal layers of the epithelium are likely exposed to LA concentrations $<1 \%$. Consistent with this, FRT vaginal (VK2), ectocervical (Ect), or endocervical (End) epithelial cells cultured to confluency in tissue culture plates and exposed to LA concentrations $>0.1 \%$ exhibited $>90 \%$ loss of cell viability (data not shown). We therefore optimized a culture system where LA-containing media was added apically to FRT epithelial cells seeded onto transwell cell culture inserts with a high density of small pores $(0.4 \mu \mathrm{m})$. The rationale of this approach was to allow rapid diffusion of LA through the cells and access to neutral basilar side media mimicking an underlying capillary-perfused tissue, to more closely mimic LA diffusion through the FRT epithelium in vivo. L- or D-LA-containing treatment media were adjusted to $\mathrm{pH} 3.9$, based on the $\mathrm{p} K_{\mathrm{a}}$ of LA (3.86) to ensure the presence of the active, protonated form of $\mathrm{LA}^{25}$ and because it is within the physiological $\mathrm{pH}$ range for women with lactobacillus-dominated microbiota. ${ }^{26}$ Using this system, we determined that cell monolayers could be treated with LA concentrations up to $0.3 \%(\mathrm{w} / \mathrm{w})$ at $\mathrm{pH} 3.9$ with only modest effects on cell viability (Supplementary Figure 1A online). Furthermore, transelectrical epithelial resistance (TEER) measurements from Ect epithelial cells confirmed that treatment with $0.3 \%$ L-LA did not alter the integrity of the cell monolayer (Supplementary Figure 1B). These data demonstrate that FRT epithelial cells cultured in our transwell system can tolerate apically applied LA at low $\mathrm{pH}$ found in the FRT.

\section{L-LA elicits an anti-inflammatory response from unstimulated cervicovaginal epithelial cells}

Given the ability of cultured lactobacilli to dampen the inflammatory response of cervicovaginal epithelial cells ${ }^{23}$ and that LA is the major organic acid metabolite in women 
with lactobacillus-dominated microbiota, ${ }^{26}$ we asked whether LA produced by these bacteria could reproduce this effect. We initially investigated L-LA due to our previous finding that it is a more potent HIV virucidal agent than D-LA at threshold concentrations. ${ }^{25}$ FRT epithelial cells were treated with $0.3 \% \mathrm{~L}-$ LA at $\mathrm{pH} 3.9$ and the production of inflammatory immune mediators were measured within media sampled from the apical compartment. Treatment with L-LA alone decreased production of the pro-inflammatory mediators IL- 6 and IL-8 in cervical epithelial cells that reached significance for IL-6 in Ect (Figure 1a) and for IL-8 in End cells (Supplementary Figure 3B). L-LA did not affect production of TNF, RANTES, or MIP3 $\alpha$ from Ect (Figure 1c-e), VK2, or End (Supplementary Figures 2 and 3) epithelial cell lines. In contrast, L-LA treatment was associated with a 6-, 4-, and 19 -fold increase in the production of the anti-inflammatory cytokine IL-1 receptor antagonist (IL-1RA) from VK2, End, and Ect cell lines, respectively (Figure 1f; Supplementary Figures 2F and 3F). IL-1RA exerts an anti-inflammatory effect by binding to the cell surface IL-1 receptor and preventing the inflammatory activity of the IL- $1 \alpha$ and IL- $1 \beta$ cytokines that utilize the IL-1 receptor. $^{28}$ Although L-LA did elicit a significant increase in IL- $1 \beta$ production from all cell lines (Figure 1g; Supplementary Figures $2 \mathrm{G}$ and $3 \mathrm{G}$ ), the magnitude of this effect was modest relative to the more marked production of the IL-1 $\beta$ antagonist, IL-1RA. In this regard, there was a 747-, 437-, and 1,284-fold excess of IL-1RA to IL-1 $\beta$ in L-LA-stimulated VK2, End, and Ect cells respectively, far in excess of the 10 -fold IL-1RA:IL-1 $\beta$ ratio required to inhibit IL-1 $\beta$ activity. ${ }^{29}$ Analysis of media sampled from the basolateral compartment of epithelial cells treated with LA showed a similar pattern of cytokine/chemokine production as the apical compartment, albeit at a lower concentration (not shown). These data indicate that L-LA elicits

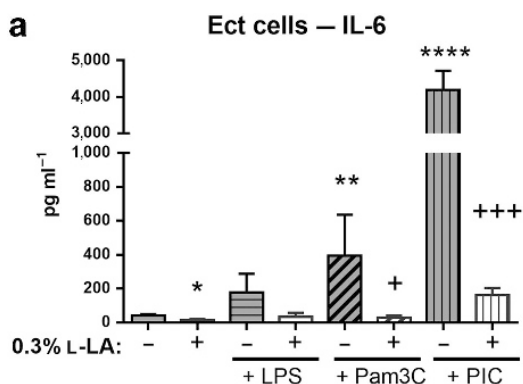

d

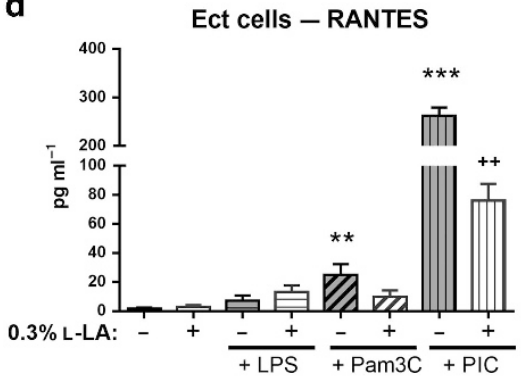

b

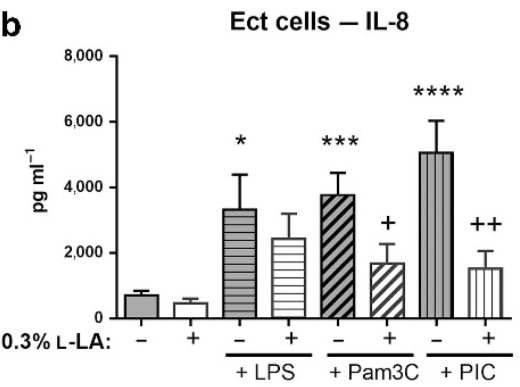

e

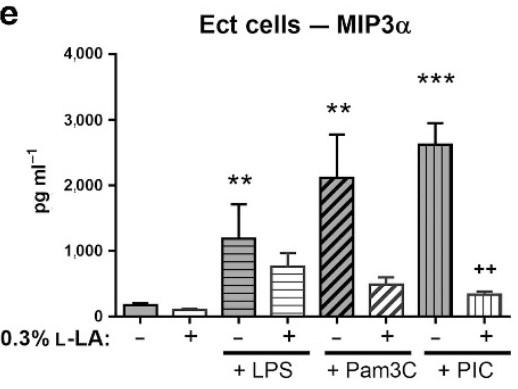

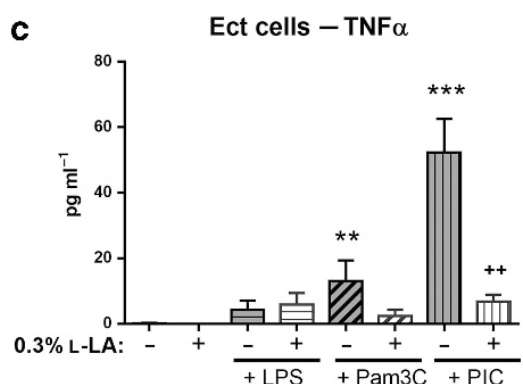

$\mathbf{f}$

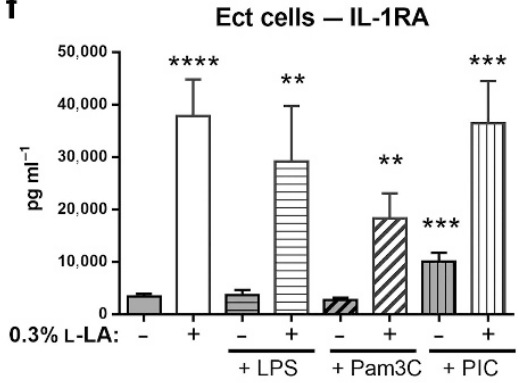

g

Ect cells - IL-1 $\beta$

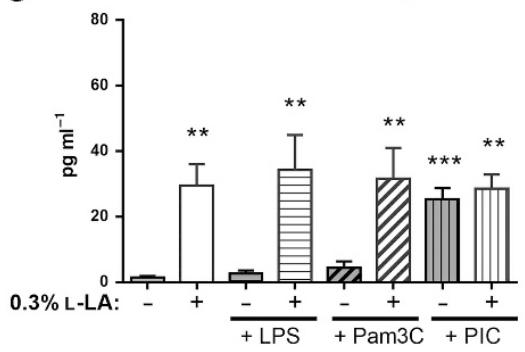

Figure 1 Lactic acid (LA) elicits an anti-inflammatory response and decreases inflammatory mediators induced by Toll-like receptor (TLR) agonists from cervicovaginal epithelial cell lines. Immortalized ectocervical epithelial cells (Ect) were cultured to confluence on transwell inserts then apically stimulated with the TLR agonists lipopolysaccharide (LPS, TLR4), Pam3CSK4 (Pam3C, TLR1/2), or polyinosinic-polycytidylic acid (PIC, TLR3) for 18 $\mathrm{h}$ in the absence or presence of $0.3 \%$ L-LA at pH 3.9 or media alone as indicated. The presence of IL-6 (a), IL-8 (b), TNF $\alpha$ (c), RANTES (d), MIP3 $\alpha$ (e), IL-1RA (f), and IL-1 $\beta(\mathbf{g})$ was detected in supernatants collected from the apical chamber using a Luminex-based cytokine assay. A similar pattern of cytokine production was observed in supernatants collected from the basolateral chamber (not shown). Graphs show mean and s.e.m. from $\geq 4$ independent assays. Statistically significant differences between treatments were tested using the Mann-Whitney $U$-test. *, ${ }^{\star *}$, ${ }^{\star \star \star}$, and ${ }^{\star \star \star \star}$ denote $P<0.05,0.01,0.001$, and 0.0001 , respectively, as compared to untreated cells. ${ }^{+},{ }^{++}$, and ${ }^{++}+$denote $P<0.05,0.01$, and 0.001 , respectively, as compared to cells treated with corresponding TLR agonist alone. 
an anti-inflammatory response from cervicovaginal epithelial cell lines.

\section{L-LA inhibits inflammatory responses from cervicovaginal epithelial cell lines elicited by TLR agonists}

Having established an anti-inflammatory effect of L-LA on unstimulated epithelial cells, we next determined whether L-LA could protect FRT epithelial cells from pathogen-mediated inflammation by treating cells with TLR agonists in the absence or presence of $0.3 \% \mathrm{~L}-\mathrm{LA}$ ( $\mathrm{pH}$ 3.9). We analyzed TLR2, 3 , and 4 agonists to mimic activation by a broad range of viruses and $\mathrm{BV}$-associated bacteria, and due to the ability of the HIV gp120 protein to elicit pro-inflammatory cytokine production through TLR2 and TLR4. ${ }^{30}$ Stimulation of Ect epithelial cells with TLR1/2 and TLR3 agonists resulted in significantly increased production of the pro-inflammatory factors IL-6, TNF, IL-8, RANTES, and MIP3 $\alpha$, whereas TLR4 stimulation was associated with significant increases in MIP $3 \alpha$ and IL-8 (Figure 1a-e). The presence of $0.3 \%$ L-LA significantly impaired, and for some cytokines (e.g., TNF and IL-6) almost completely abolished, the TLR-mediated production of inflammatory factors (Figure 1a-e). In contrast, the ability of L-LA to elicit IL-1RA production was unaffected by the presence of TLR agonists (Figure 1f). An identical effect was observed in both VK2 and End epithelial cell lines (Supplementary Figures 2 and 3 ).

To confirm that L-LA was acting directly on the cell and not indirectly on the TLR agonist, Ect cells were pretreated with $0.3 \% \mathrm{~L}-\mathrm{LA}$ for $1 \mathrm{~h}$, prior to removal of the L-LA-containing media, extensive washing, and subsequent stimulation with the TLR3 agonist polyinosinic-polycytidylic acid (PIC). PIC-elicited pro-inflammatory mediator production was significantly impaired from cells which had been pretreated with L-LA but not from cells treated with pH 3.9 media alone (Supplementary Figure 4A-C). The activity of PIC and the TLR1/2 agonist Pam3C was also unaffected by pretreatment with L-LA or low-pH media prior to neutralization and addition to cells (data not shown), further excluding the likelihood that LA acts directly on TLR agonists. These data demonstrate that L-LA acts directly on cervicovaginal epithelial cell lines to dampen the production of pro-inflammatory mediators elicited by bacterial and viral pathogen-associated molecular patterns, and mediates the production of IL-1RA in the absence or presence of these pathogen-associated molecular patterns.

\section{The anti-inflammatory effect of L-LA on cervicovaginal epithelial cell lines is not due to acidity alone}

Given the observation that the anti-inflammatory effect of LA was only observed at low $\mathrm{pH}$, we next confirmed that the effect was not solely due to acidity alone. Ect cells were incubated with media acidified to $\mathrm{pH} 3.9$ with $\mathrm{HCl}$ in the absence or presence of PIC stimulation. In these experiments, the HCl-containing media was regularly refreshed to compensate for the reduced buffering capacity of $\mathrm{HCl}$ as compared to LA, and a similar low $\mathrm{pH}$ was maintained throughout the $1 \mathrm{~h}$ treatment period for both $\mathrm{HCl}$ - and L-LA-treated cells. Unlike L-LA, treatment with low-pH media was not associated with a significant reduction in PIC-elicited pro-inflammatory cytokine production (Figure 2). Although there was a trend toward a moderate decrease in some PIC-elicited pro-inflammatory factors in the presence of $\mathrm{HCl}$-acidified media (i.e., IL-6 $(P=0.33)$ and RANTES $(P=0.10)$ for PIC vs. PIC $+\mathrm{HCl}$-treated samples, Figure 2 c,d), which was of borderline significance for MIP3 $\alpha$ $(P=0.051$, Figure 2e), the magnitude of this effect was substantially less than that seen with L-LA. Further, HClacidified media were unable to stimulate IL-1RA production (Figure 2f). These findings confirm that acidity alone is not solely responsible for the anti-inflammatory effects of LA.

\section{L-LA and D-LA inhibit TLR agonist-elicited inflammatory responses from cervicovaginal epithelial cell lines mediated through the protonated form of LA}

LA within the lower FRT exists as a mixture of $\mathrm{L}$ - and D-isomers at $\sim 110 \mathrm{~mm}(1 \% \mathrm{w} / \mathrm{w})$, and is in equilibrium between the uncharged protonated form and the charged lactate anion depending on the $\mathrm{pH}\left(\mathrm{p} K_{\mathrm{a}}\right.$ of $\left.\mathrm{LA}=3.86\right){ }^{26,31}$ We therefore investigated whether the anti-inflammatory effect was unique to the protonated, L-isomer of LA by treating Ect cells with $0.3 \%$ D-LA at $\mathrm{pH} 3.9$, or with $\mathrm{L}-\mathrm{LA}$ which had been neutralized to $\mathrm{pH}$ 7.4. Treatment with D-LA or neutralized L-LA had minimal effect on cell viability and did not alter the integrity of the epithelial monolayer (Supplementary Figure 1). Similar to L-LA, D-LA elicited high-level production of the antiinflammatory cytokine IL-1RA (Figure 3a) and was able to inhibit PIC-mediated production of the pro-inflammatory factors IL-6, TNF, RANTES, IL-8, and MIP3 $\alpha$ (Figure $3 \mathbf{b}-\mathbf{f}$ ). No significant difference was detected between the ability of L-LA and D-LA to elicit this anti-inflammatory effect. In contrast, L-LA neutralized to $\mathrm{pH} 7.4$ prior to addition to FRT epithelial cells did not alter IL-1RA production nor significantly inhibit pro-inflammatory factor production (Figure 3). Taken together, these data demonstrate that both L-LA and D-LA elicit an anti-inflammatory response from FRT epithelial cell lines and prevent TLR-induced inflammation, and that this effect is mediated by the protonated form of LA, which predominates at low $\mathrm{pH}$.

\section{L-LA elicits an anti-inflammatory response from primary cervicovaginal epithelial cells and tissues}

The anti-inflammatory effect of L-LA observed in FRT epithelial cell lines was next confirmed using primary vaginal-ectocervical epithelial cells cultured on transwells. These cells were derived from the FRT tissue of women undergoing hysterectomies for benign indications as previously described. ${ }^{32}$ Similar to the effect observed in cell lines, L-LA significantly impaired the PIC-elicited production of the proinflammatory factors IL-6, TNF, and RANTES from primary vaginal-ectocervical epithelial cells (Figure $4 \mathbf{a}-\mathbf{c}$ ). A similar trend was also observed for IL- 8 and MIP $3 \alpha$ production (Supplementary Figure 5A,B), and this effect was reproduced in a different preparation of vaginal epithelial cells ("V19"; Supplementary Figure 5C-H). Moreover, treatment with $0.3 \%$ L-LA ( $\mathrm{pH}$ 3.9) significantly increased the production of IL-1RA from primary epithelial cells (Figure 4d). These data confirm 

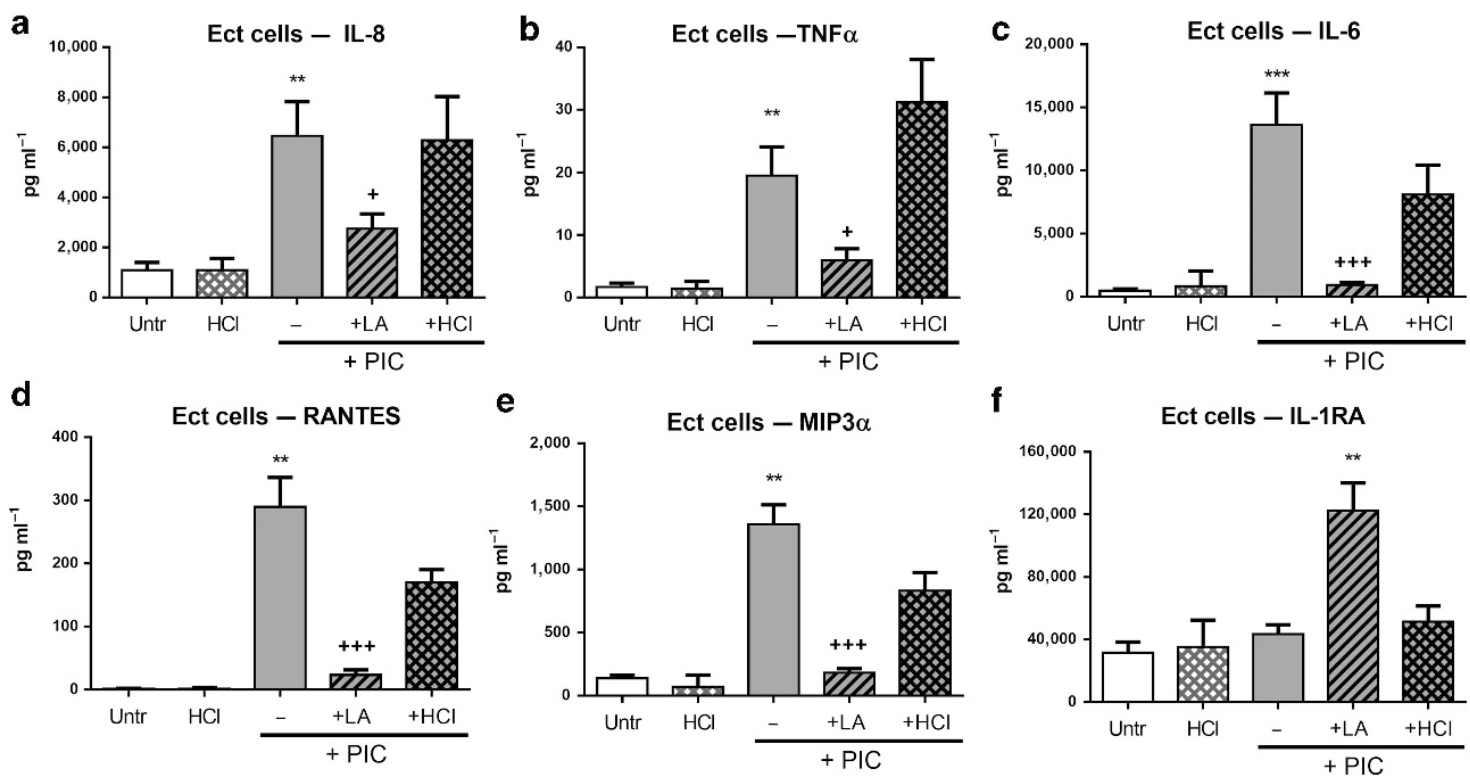

Figure 2 The anti-inflammatory effect of L-lactic acid (L-LA) on cervicovaginal cell lines is not due to acidity alone. Ect cells were stimulated with polyinosinic-polycytidylic acid (PIC) for $1 \mathrm{~h}$ in the absence or presence of $0.3 \% \mathrm{~L}-\mathrm{LA}(\mathrm{pH} 3.9)$ or media acidified to $\mathrm{pH} 3.9 \mathrm{with} \mathrm{HCl}(\mathrm{HCl})$ and compared to cells treated with $\mathrm{HCl}$ alone or untreated as indicated. Treatments containing $\mathrm{HCl}$ were replenished every 15 min during the treatment period to maintain low $\mathrm{pH}$. The presence of IL-8 (a), TNF $\alpha(\mathbf{b})$, IL-6 (c), RANTES (d), MIP-3 $\alpha(\mathbf{e})$, and IL-1RA (f) in culture supernatants collected from the apical chamber was detected as described in the legend of Figure 1. Graphs show mean and s.e.m. from $\geq 5$ independent assays. Statistically significant differences between treatments were tested using the Mann-Whitney U-test. ${ }^{* *}$ and ${ }^{* * *}$ denote $P<0.01$ and 0.001 , respectively, as compared to untreated cells. ${ }^{+}$and ${ }^{++}$denote $P<0.05$ and 0.001 , respectively, as compared to cells treated with PIC alone.

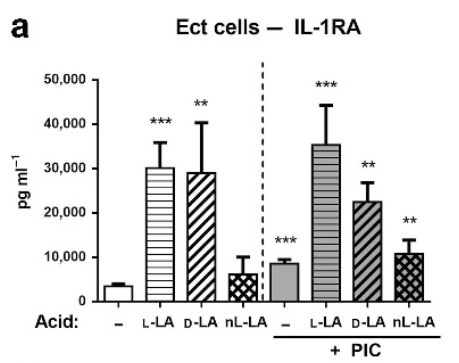

d

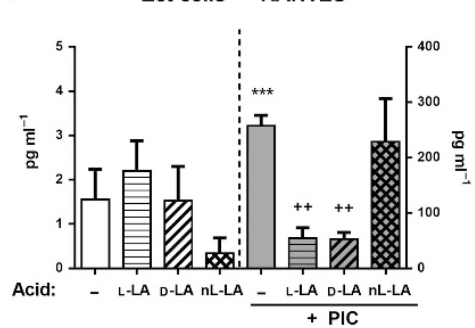

b

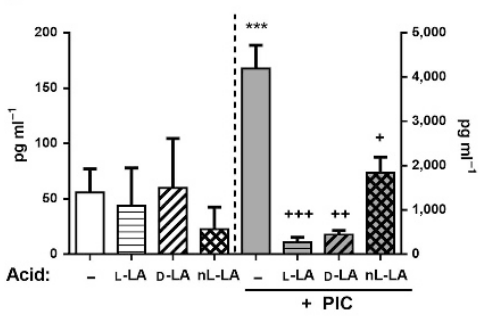

e

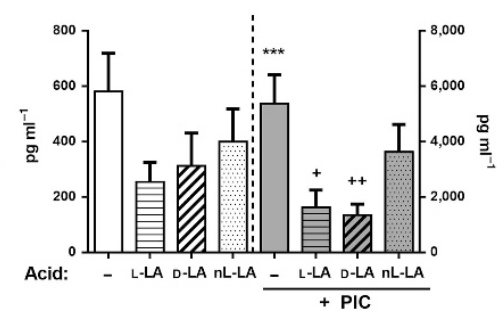

C Ect cells - TNF $\alpha$

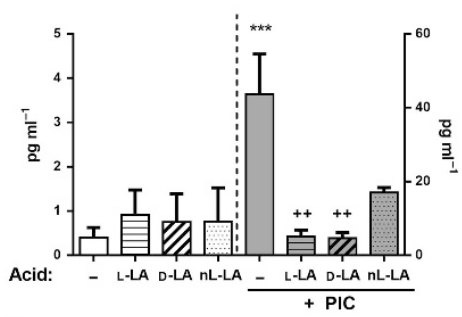

f

Ect cells - MIP3 $\alpha$

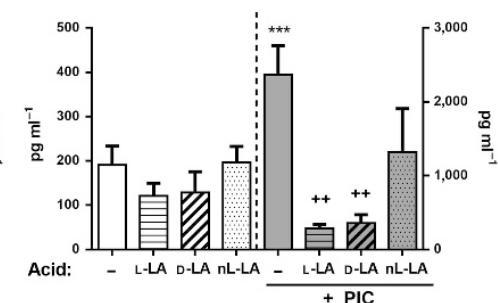

Figure 3 L-lactic acid (L-LA) and D-LA inhibit TLR-agonist-mediated inflammatory responses from cervicovaginal epithelial cell lines through the protonated form of LA. Ect cells were stimulated with polyinosinic-polycytidylic acid (PIC) for $18 \mathrm{~h}$ in the absence or presence of $0.3 \% \mathrm{~L}$-LA or D-LA (both pH 3.9), 0.3\% L-LA neutralized to pH 7.4 (nL-LA) or media alone as indicated. The presence of IL-1RA (a), IL-6 (b), TNF $\alpha$ (c), RANTES (d), IL-8 (e), and MIP3 $\alpha$ (f) in culture supernatants collected from the apical chamber was detected as in the legend of Figure 1. Graphs show mean and s.e.m. from $\geq 4$ independent assays. Statistically significant differences between treatments were tested using the Mann-Whitney $U$-test. ${ }^{* \star}$ and ${ }^{\star \star \star}$ denote $P<0.01$ and 0.001 , respectively, as compared to untreated cells. ${ }^{+},{ }^{++}$, and ${ }^{++}$denote $P<0.05,0.01$ and 0.001 , respectively, as compared to cells treated with PIC alone.

that LA is capable of protecting primary FRT epithelial cells from TLR-induced inflammation, which may be elicited by pathogens and commensal bacteria present in the FRT.

We next investigated whether the anti-inflammatory effect of LA observed in epithelial cell monolayers could be reproduced from cells in a relevant multilayer organotypic tissue model of the FRT epithelium. For these experiments, we used the EpiVaginal reconstructed human vaginal epithelial tissue model (VEC-100, MatTek), which is composed of healthy primary vaginal epithelial cells in a highly differentiated 
a

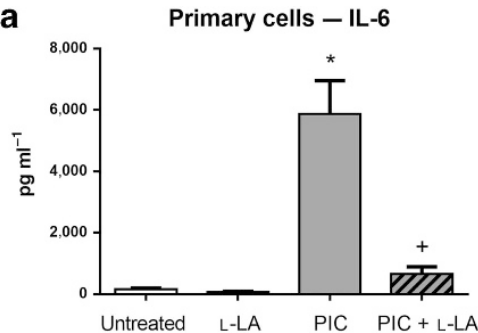

d

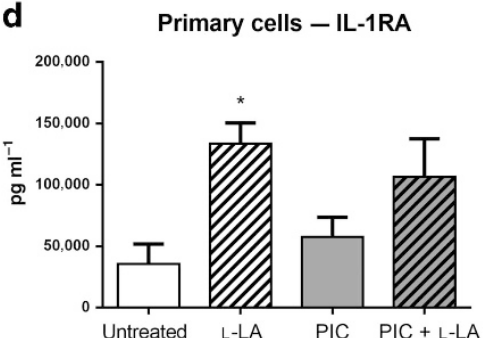

b

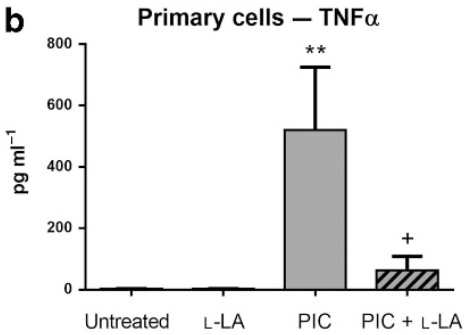

e

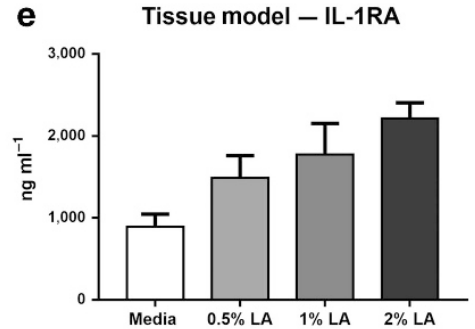

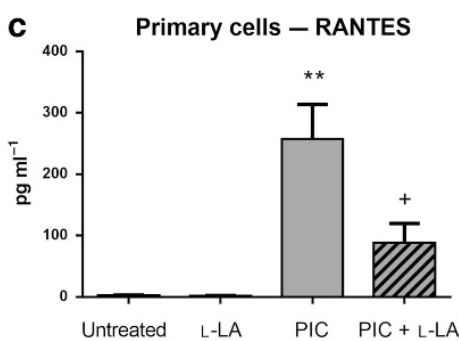

f

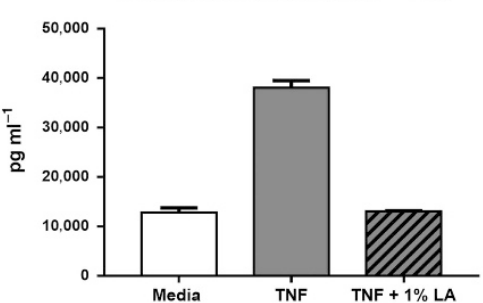

Figure 4 L-lactic acid (L-LA) elicits an anti-inflammatory response from both primary vaginal-ectocervical cells and an organotypic tissue model of female reproductive tract epithelium. Primary cervicovaginal cells (a-d) were stimulated with polyinosinic-polycytidylic acid (PIC) for $1 \mathrm{~h}$ in the absence or presence of $0.3 \% \mathrm{~L}-\mathrm{LA}(\mathrm{pH} \mathrm{3.9})$ and compared to cells treated with $0.3 \% \mathrm{~L}-\mathrm{LA}(\mathrm{pH} 3.9)$ alone or untreated as indicated. The presence of IL-6 (a), TNF $\alpha(\mathbf{b})$, RANTES (c), and IL-1RA (d) in culture supernatants was detected as described in the legend of Figure 1. Graphs show mean and s.e.m. from $\geq 4$ independent assays. Statistically significant differences between treatments were tested using the Mann-Whitney $U$-test. * and ${ }^{* *}$ denote $P<0.05$ and 0.01 , respectively, as compared to untreated cells. + denotes $P<0.05$ as compared to cells treated with PIC alone. The EpiVaginal organotypic vaginal epithelial tissue model was treated with media containing physiological concentrations of L-LA and IL-1RA in the apical supernatant was measured after $18 \mathrm{~h}(\mathbf{e})$. Alternatively, EpiVaginal tissue was treated with TNF in the absence or presence of 1\% L-LA (pH 3.9) for $3 \mathrm{~h}$ and the concentration of IL-8 in the apical supernatant was measured $18 \mathrm{~h}$ after treatment (f). A similar pattern of cytokine production was observed in supernatants collected from the basolateral chamber (not shown). Graphs show mean and s.e.m. from one experiment that was representative of $n=3$ individual experiments.

structure consisting of basal, supra-basal, and surface glycogencontaining epithelial cell layers that closely resemble the structure of human vaginal explants. ${ }^{32}$ In addition, the tissue model allowed evaluation of higher physiological concentrations of LA (up to $2 \% \mathrm{w} / \mathrm{w}$ ) that did not show signs of cytotoxicity or impact on epithelial integrity as determined by the 3-[4, 5-dimethylthiazolyl-2]-2, 5-diphenyltetrazolium bromide assay and TEER, respectively (data not shown). Treatment of the apical surface of the EpiVaginal tissue with L-LA elicited the production of IL-1RA in a dose-dependent manner (Figure 4e). A similar increase in IL-1RA was also observed with D-LA (data not shown). To investigate whether L-LA could also mitigate the effects of an inflammatory stimulus, tissues were apically stimulated with TNF in the absence or presence of $1 \%$ L-LA. TNF-induced the production of the pro-inflammatory cytokine IL- 8 and this was inhibited by the presence of 1\% L-LA (Figure 4f), confirming that LA has an anti-inflammatory effect on FRT epithelial cells within a physiologically relevant, multilayer tissue model.

\section{L-LA can protect cells from subsequent TLR-agonist- mediated inflammation following only $1 \mathrm{~h}$ of LA exposure} Our assay system was specifically designed to allow diffusion of LA through the epithelial cell monolayer. However, a consequence of this was that the low $\mathrm{pH}$ of the treatment media applied to the upper chamber was increasingly neutralized during the treatment period in such a way that after $2-3 \mathrm{~h}$, the $\mathrm{pH}$ of the treatment media rose above the $\mathrm{p} K_{\mathrm{a}}$ of LA, where the majority of LA would be in the non-protonated form. Given that LA mediates its immune modulatory effects through the protonated form, this suggests that the anti-inflammatory effect of LA was likely elicited during 1-2 h of treatment. We therefore conducted a stimulation time course of Ect cells treated with L-LA in the absence or presence of PIC for 1-18 h and confirmed that even $0.5 \mathrm{~h}$ stimulation with L-LA was able to elicit significant levels of IL-1RA production and abolish PIC-induced pro-inflammatory cytokine production (Supplementary Figure 6).

L-LA mediates an anti-inflammatory effect on FRT epithelial cells exposed to either cervicovaginal or seminal fluids

In vivo, FRT epithelial cells are exposed to cervicovaginal fluid (CVF), which contains a milieu of immunomodulatory factors that can influence cellular activation and response to stimulation. To confirm the anti-inflammatory effect of L-LA in the context of CVF-exposed cells, Ect epithelial cells were preincubated with noncytotoxic concentrations of diluted, pooled CVF for $4 \mathrm{~h}$, then stimulated with $0.3 \% \mathrm{~L}-\mathrm{LA}(\mathrm{pH} 3.9)$, and the TLR agonist PIC both alone and in combination. Interestingly, the viability of Ect cells treated with L-LA following CVF exposure (mean viability 94\%, Figure 5a) appeared to be greater than that observed in cells treated with L-LA alone (mean viability $80.3 \%$, Supplementary Figure 1), possibly implying a protective effect of CVF. L-LA elicited IL-1RA production (Figure 5b) and was able to mitigate PIC-induced IL- 6 and TNF production from cells that had been pre-exposed to CVF (Figure 5c,d). These data confirm the anti-inflammatory activity of L-LA in the context of CVF-exposed epithelial cells. 

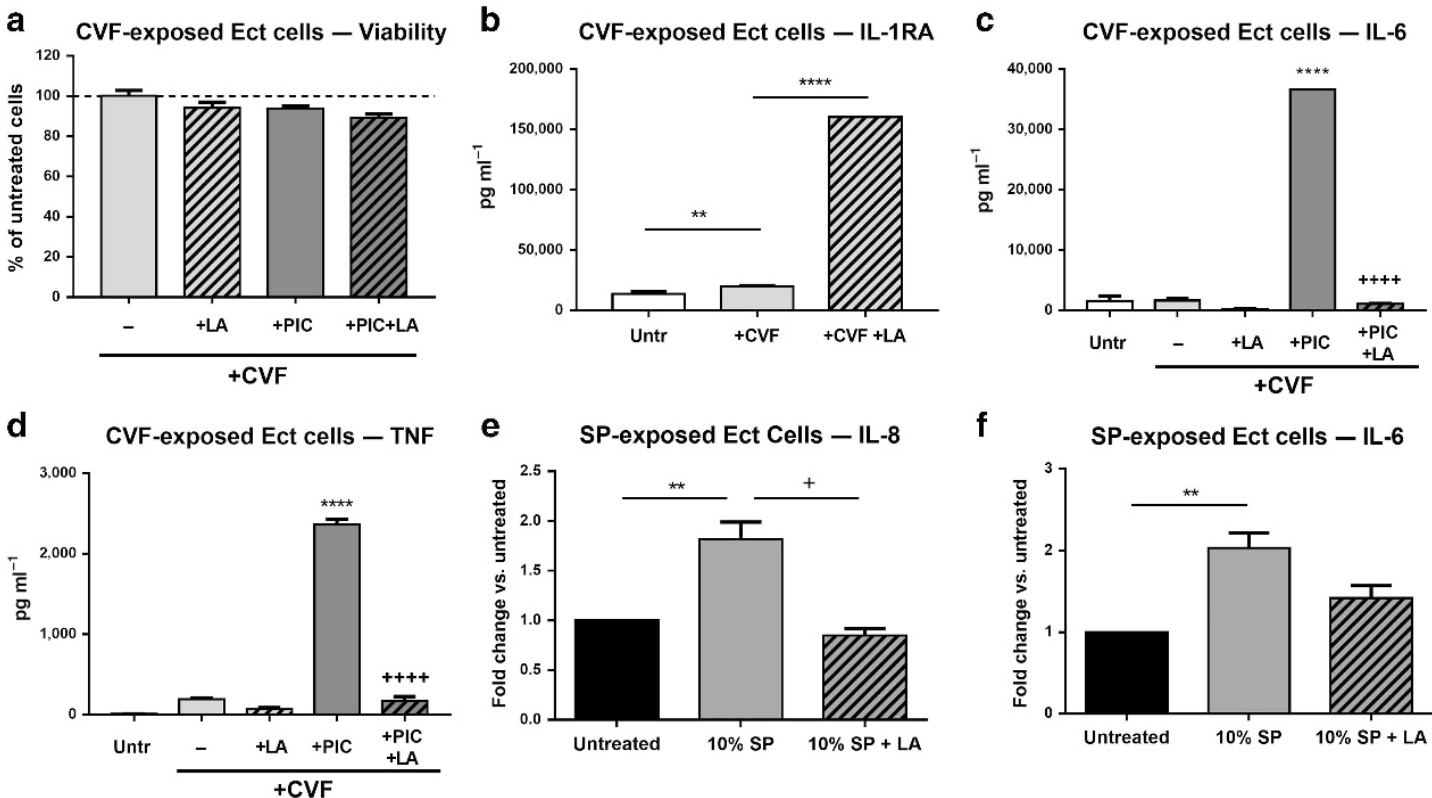

$\mathbf{f}$

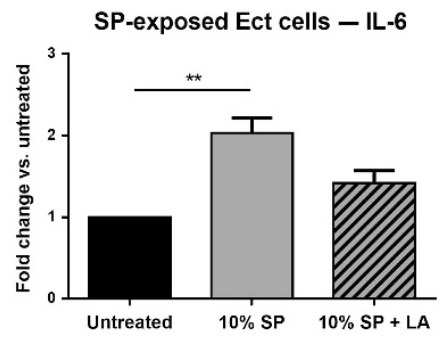

Figure 5 L-lactic acid (L-LA) elicits an anti-inflammatory effect on female reproductive tract epithelial cells pretreated with cervicovaginal fluid (CVF) and in the presence of seminal plasma. (a-d) Ect cells were stimulated with CVF diluted $1 / 3$ in media for $4 \mathrm{~h}$, washed, then stimulated with $0.3 \% \mathrm{~L}-\mathrm{LA}$ ( $\mathrm{pH} 3.9$ ) and/or polyinosinic-polycytidylic acid (PIC) for $1 \mathrm{~h}$, washed again then cultured for an addition 18-24h. Cell viability was determined by the CellTiter 96 AQueous One Solution Cell Proliferation Assay (a). The production of IL-1RA (b), IL-6 (c), and TNF $\alpha$ (d) in apical supernatants was measured using a Luminex-based cytokine assay. (e,f) Ect cells were stimulated with media containing $10 \%$ seminal plasma (SP) for $12 \mathrm{~h}$ in the absence or presence of $0.3 \% \mathrm{~L}-\mathrm{LA}(\mathrm{pH} 3.9)$, washed, then cultured for an additional 18-24 h. The production of IL-8 (e) and IL-6 (f) was measured in the apical supernatants as above and expressed as a ratio to untreated cells. Graphs show mean and s.e.m. from $n=3$ (a-d) or 4 (e-f) independent assays. IL-1RA values for some CVF-treated cells were above the limit of quantification of the cytokine assay, and were thus assigned the value of the most concentrated assay standard. Statistically significant differences between treatments were tested using a Student's $t$-test $(\mathbf{a}-\mathbf{d})$ or Mann-Whitney $U$-test $(\mathbf{e}-\mathbf{f}){ }^{*}{ }^{* \star}$ and ${ }^{* * * *}$ denote $P<0.01$ and $P<0.0001$, respectively, as compared to untreated cells, whereas ${ }^{+}$and ${ }^{+++}$denote $P<0.05$ and $P<0.0001$, respectively, as compared to cells treated with PIC or SP alone.

During unprotected sexual intercourse, FRT epithelial cells are also exposed to seminal plasma, which is known to elicit an inflammatory response in the FRT of mammals ${ }^{33}$ and treatment of human FRT epithelial cells with seminal plasma increases pro-inflammatory cytokine production. ${ }^{34}$ We therefore determined whether LA was able to prevent seminal plasma-mediated inflammation. Consistent with Sharkey et al. ${ }^{34}$ overnight stimulation of Ect epithelial cells with media containing $10 \%$ seminal plasma resulted in a significant increase in the production of the pro-inflammatory cytokines IL-8 and IL-6 (Figure 5e,f), with no effects on cell viability (data not shown). This pro-inflammatory effect was diminished by the presence of $0.3 \%$ L-LA (pH 3.9, Figure 5e,f), confirming that LA is able to prevent not only pathogen-mediated production of pro-inflammatory immune mediators but also inflammation due to exposure of FRT epithelial cells to seminal plasma during heterosexual intercourse.

\section{L-LA inhibits pro-inflammatory cytokine production at a stage prior to gene transcription}

To determine whether LA inhibits pro-inflammatory cytokine production at a step prior to gene transcription, we measured expression of the pro-inflammatory factors $\mathrm{Il}-6, \mathrm{Tnf}$, and Rantes after $4 \mathrm{~h}$ incubation following $1 \mathrm{~h}$ stimulation with PIC in the presence or absence of $0.3 \% \mathrm{~L}-\mathrm{LA}$ ( $\mathrm{pH}$ 3.9). PIC treatment was associated with a median four- to sixfold increased expression of Il-6, Tnf, and Rantes, which was significantly inhibited by the presence of L-LA (Figure 6). These data indicate that L-LA mediates its anti-inflammatory effects on FRT epithelial cells by acting at a stage upstream of gene transcription.

\section{DISCUSSION}

Increasing evidence suggests that FRT microbial communities play an important role in influencing sexual and reproductive health outcomes in women. Recent studies have linked the presence of polymicrobial bacterial communities, including those found in BV, with inflammation in the FRT and increased risk of HIV infection, ${ }^{10,12-14}$ suggesting that genital inflammation associated with certain FRT microbiota may increase HIV/STI transmission. Although it is known that women with lactobacillus-dominated microbiota have a reduced risk of HIV and STI infection, ${ }^{5,6,13}$ the mechanisms responsible for this effect are unknown. Here we investigated the effect of LA, the major organic acid metabolic product of Lactobacillus spp., on cervicovaginal epithelial cells from the FRT to determine whether the positive sexual health outcomes associated with lactobacilli may be mediated through an immunomodulatory effect of LA on epithelial cells of the FRT.

We found that LA acts directly on cervicovaginal epithelial cells to induce an anti-inflammatory state, characterized by 

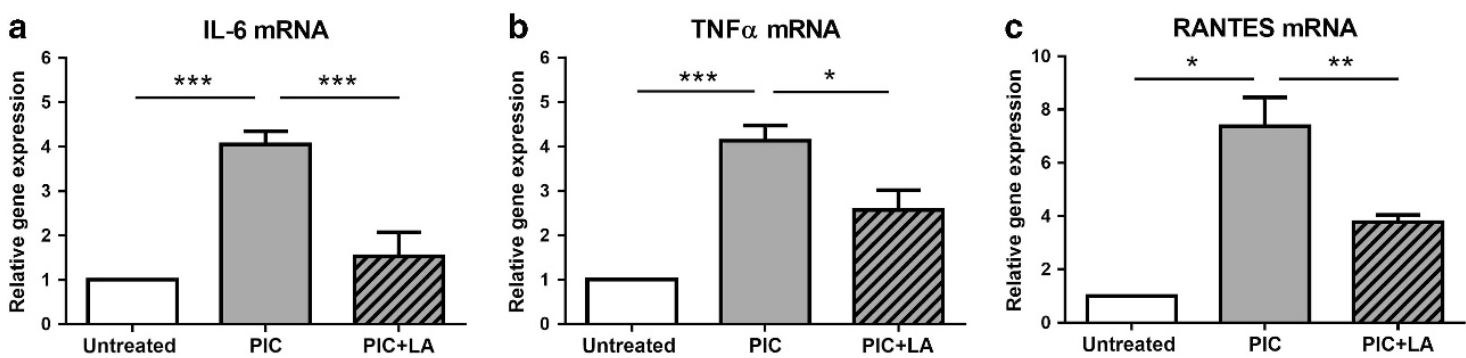

Figure 6 L-lactic acid (L-LA) inhibits pro-inflammatory immune mediator production at a stage prior to gene transcription. Ect cells were stimulated with polyinosinic-polycytidylic acid (PIC) in the absence or presence of $0.3 \% \mathrm{~L}-\mathrm{LA}(\mathrm{pH} 3.9)$ or left untreated for $1 \mathrm{~h}$, treatment media removed, and cells cultured for an additional $4 \mathrm{~h}$. RNA was isolated from cells and expression of II-6 (a), Tnfa (b), and Rantes (c) genes was measured by quantitative PCR with reverse transcription. Gene expression was standardized to the housekeeping gene Gapdh and expressed as a fold change over untreated cells using the $\Delta \Delta \mathrm{C}_{\mathrm{T}}$ method. Graphs show mean and s.e.m. from $\geq 4$ individual experiments. ${ }^{*}$, ${ }^{\star *}$, and ${ }^{\star * *}$ denote $P<0.05,0.01$, and 0.001 , respectively, compared to untreated cells as determined using the Mann-Whitney U-test.

substantially heightened production of the anti-inflammatory cytokine IL-1RA, and a modest reduction in pro-inflammatory cytokine production in Ect and End cell lines. Furthermore, LA was able to protect cervicovaginal epithelial cells from TLR agonist-elicited inflammation, with significantly impaired production of the inflammatory cytokines and chemokines in the presence of LA. This effect was observed not only in cervicovaginal epithelial cell lines but also in primary vaginal epithelial cells and importantly in an organotypic threedimensional tissue model of the FRT epithelium, confirming the physiological relevance of our observations. The ability of LA to prevent the production of pro-inflammatory mediators from cervicovaginal epithelial cell lines in response to TLR2, 3, and 4 agonists suggests that LA can inhibit inflammation induced by pathogen-associated molecular patterns that comprise a broad range of pathogenic bacteria and viruses. Given that immune mediators such as IL-6, TNF, and MIP3 $\alpha$ activate and recruit HIV target cells in the FRT epithelium and potentiate HIV replication, ${ }^{10,17,18}$ we hypothesize that the ability of LA to inhibit the production of these mediators from cervicovaginal cells is likely to mitigate HIV transmission in vivo.

This study provides some of the first data demonstrating the anti-inflammatory effect of LA on cervicovaginal epithelial cells, although our findings are in contrast with a previous study, which reported that L-LA potentiated TLR3-mediated production of IL-8 from VK2 cell monolayers. ${ }^{35}$ Notably, in our hands, the addition of comparable concentrations of L-LA to standard epithelial cell cultures resulted in dramatic cytotoxicity. We utilized a transwell culture system to enable evaluation of the immunomodulatory effects of L-LA under noncytotoxic conditions and found that LA inhibited inflammation elicited by TLR1/2, TLR3, and TLR4 agonists and by seminal plasma. This is particularly relevant for HIV infection given that the HIV gp120 protein elicits inflammation through activation of TLR2 and TLR4 (ref. 30) and stimulation of TLR3 and TLR4 activates the HIV long terminal repeat involved in HIV transcription. ${ }^{18}$ Our data suggest that the ability of Lactobacillus spp. to inhibit TLR agonist-induced inflammation when co-cultured with FRT epithelial cells ${ }^{23}$ is at least in part mediated by the action of LA. We found that the antiinflammatory effect of LA was mediated by the protonated form present at low $\mathrm{pH}$, and while low $\mathrm{pH}$ alone could not reproduce the extent of this effect, it is possible that low $\mathrm{pH}$ potentiates the effect of LA in vivo. The anti-inflammatory effect of LA was not limited to the L-isomer, as we observed a similar response with equivalent concentrations of D-LA, suggesting that LA can elicit an anti-inflammatory effect in women with lactobacillus-dominated microbiota irrespective of whether the dominant Lactobacillus spp. produces both L-LA and D-LA (e.g., L. crispatus) or predominantly D-LA (e.g., L. jensenii). ${ }^{36}$ Further work is required to investigate the full effect of L-LA and D-LA isomers on gene expression in FRT epithelial cells and identify any differential effects of distinct ratios of the LA isomers produced by various Lactobacillus spp. ${ }^{36}$

In addition to their effects on cervicovaginal epithelial cells, ${ }^{23}$ Lactobacillus spp. and cultured media from LA-producing bacteria have an anti-inflammatory effect on other cell types including peripheral blood mononuclear cells and monocytes/ macrophages, with the mechanism thought to be through inhibiting nuclear import and activation of the transcription factor NF- $\kappa \mathrm{B}$, which promotes the transcription of a number of pro-inflammatory target genes, including IL- $1 \alpha / \beta$ and TNF $\alpha .{ }^{37,38}$ LA alone has been shown to inhibit lipopolysaccharide-induced inflammation in monocytes by inhibiting the degradation of I $\kappa \mathrm{B}$ proteins that bind NF- $\kappa \mathrm{B}$ complexes and ensure they remain in an inactive state within the cytoplasm. ${ }^{39}$ These studies are consistent with our finding that LA attenuates cytokine mRNA transcription. Our observation that L-LAcontaining media neutralized to $\mathrm{pH} 7.4$ failed to elicit an antiinflammatory state indicates that protonated LA, and not the lactate anion, was the active form.

Three important findings in this study have implications for the potential use of LA-containing microbicides to prevent inflammation and mitigate STI acquisition risk in women: (1) treatment of cervicovaginal epithelial cells with LA for as little as $0.5-1 \mathrm{~h}$ was sufficient to elicit an anti-inflammatory response, (2) pretreatment of cells with LA was able to protect from a subsequent inflammatory challenge, and (3) LA was able to protect cells from a range of inflammatory stimuli including 
TLR agonists, TNF, and seminal plasma. The ability of LA to inhibit seminal plasma-mediated inflammation suggests that it may also mitigate the recruitment of $\mathrm{CD} 4+\mathrm{T}$ cells into the cervix, which occurs following coitus. ${ }^{40}$ These properties suggest LA-containing microbicides may be able to elicit an immunomodulatory effect relatively quickly after application, and could be used regularly and/or prior to sexual exposure to maintain lower FRT health and protect against inflammatory challenges from a range of pathogens and seminal plasma. In this regard, an intravaginal ring providing sustained release of LA was recently demonstrated to be safe and well tolerated in a small phase I trial and could represent a tractable LA delivery system. ${ }^{41}$

A number of early clinical trials have evaluated the safety and tolerability of lactobacillus-containing agents in the lower FRT and their efficacy against BV. Administration of live L. crispatus to women with BV was found to be safe and well tolerated in a small phase II trial, ${ }^{42}$ whereas supplementation of traditional treatments for BV with oral lactobacillus probiotics significantly increased the proportion of women who remained BV free during follow-up. ${ }^{43}$ The safety and efficacy of the vaginal gel Acidform that contains 2\% LA have also been evaluated in a small randomized placebo controlled trial, which found that Acidform use resulted in a significant reduction in vaginal $\mathrm{pH}$, but was associated with increased mucosal irritation and reduced levels of IL-1RA in cervicovaginal lavage. ${ }^{44}$ Our finding of significantly increased production of IL-1RA from cervicovaginal cells and epithelial FRT tissue models following LA administration is inconsistent with this latter finding. This may be due to the higher concentration of LA in Acidform, the action of other agents within the gel that may mask the antiinflammatory effects of LA, or the presence of a milieu of immune modulators generated by both FRT-resident bacteria and host cells that may modulate the effects of LA in vivo. Further studies are warranted to characterize the immunomodulatory effects of LA-containing vaginal gels in vivo and determine their ability to treat and prevent FRT conditions such as BV as well as protect against STI infection.

Topical microbicides are a promising tool for femaleinitiated prevention strategies against HIV infection and are urgently required in regions such as sub-Saharan Africa where young women and female partners of HIV-positive men may not be sufficiently empowered to negotiate condom use. Several microbicides have been developed to date including a vaginal gel containing the HIV reverse transcriptase inhibitor tenofovir (TFV). ${ }^{45}$ However, the efficacy of TFV-containing microbicides could potentially be diminished by innate immune activation ${ }^{46}$ and in vitro studies have shown that TFV elicits the production of pro-inflammatory cytokines from both primary cervicovaginal cells and HIV target cells isolated from the FRT. ${ }^{47}$ This observation suggests that incorporating an antiinflammatory agent such as LA into microbicides may protect against potential inflammatory effects of active microbicide agents and help maintain an immuno-quiescent state to protect against HIV infection. LA could also be incorporated into alternative HIV pre-exposure prophylaxis strategies such as a vaginal ring containing the antiretroviral drug dapivirine, which has shown efficacy in recent phase III clinical trials. ${ }^{48}$ Further in vitro and in vivo characterization of the immunomodulatory properties of LA will be important to determine the potential utility of LA in female-initiated prevention strategies to protect against STI and HIV infection.

\section{METHODS}

Epithelial cell culture and stimulation. Vaginal (VK2/E6E7), endocervical (End/E6E7), and ectocervical (Ect/E6E7) epithelial cells lines from the FRT, that resemble their tissue of origin in morphology and immunochemical characteristics, ${ }^{49}$ were obtained from American Type Culture Collection (Manassas, VA) and maintained in serumfree keratinocyte medium (SFKM), supplemented with $0.1 \mathrm{ng} \mathrm{ml}^{-1}$ human recombinant epithelial growth factor, $0.05 \mathrm{mg} \mathrm{ml}^{-1}$ bovine pituitary extract (all from Life Technologies, Carlsbad, CA), $0.4 \mathrm{~mm}$ $\mathrm{CaCl}_{2}, 50 \mathrm{U} \mathrm{ml}^{-1}$ penicillin, and $50 \mu \mathrm{g} \mathrm{ml}^{-1}$ streptomycin. Primary human cervicovaginal epithelial cells were obtained from MatTek (Ashland, MA). Primary cells were derived from discarded surgical tissue from the FRT of premenopausal, otherwise healthy women undergoing hysterectomies for benign indications, and were maintained as previously described. ${ }^{49}$ Epithelial cells $(100,000$ per well) were seeded into $6.5 \mathrm{~mm}$ diameter polycarbonate transwell inserts containing $0.4 \mu \mathrm{m}$ pores (Corning, Corning, NY) in 24-well tissue culture plates and cultured for 7 days to obtain a confluent cell monolayer as confirmed by dextran diffusion analysis. Epithelial monolayers were stimulated with $0.3 \%(\mathrm{w} / \mathrm{w}) \mathrm{L}$ - or D-LA ( $\mathrm{pH} 3.9)$ in the presence or absence of the TLR agonists lipopolysaccharide (TLR4 agonist; $1 \mu \mathrm{g} \mathrm{ml}^{-1}$ ), Pam3CSK4 (Pam3C, TLR1/2 agonist; $1 \mu \mathrm{g} \mathrm{ml}^{-1}$ ), and high-molecular weight PIC (TLR3 agonist; $20 \mu \mathrm{g} \mathrm{ml}^{-1}$; all from InvivoGen, San Diego, CA) added only to the upper apical chamber of the transwell. Cells were incubated with the treatment media for $18 \mathrm{~h}$ (except for pulsing experiments where the stimulus was added for only the first hour) and supernatants were collected and stored at $-80^{\circ} \mathrm{C}$ for subsequent cytokine analysis. Cell viability was assessed following stimulation using the CellTiter 96 Aqueous One Solution Cell proliferation assay (Promega, Madison, WI). ${ }^{50}$ The integrity of the epithelial cell monolayer was assessed by measuring TEER using a Millicell ERS-2 Voltohmmeter (Merck Millipore, Billerica, MA). The effect of low $\mathrm{pH}$ was assessed by treating cells with SFKM pH 3.9 (adjusted with $\mathrm{HCl}$ ) for $1 \mathrm{~h}$ with treatment media refreshed every $15 \mathrm{~min}$ to maintain the low $\mathrm{pH}$. Some experiments were performed in Ect cells pretreated with CVF collected from women of reproductive age (18-45 years old) recruited at the Johns Hopkins University Campus using the SoftCup (Instead Inc., La Jolla, CA) as previously described.$^{51}$ CVF samples from three women were pooled, and the $\mathrm{pH}$ of the pooled CVF was 3.9. Ethical approval was obtained from Homewood Institutional Review Board, Johns Hopkins University HIRB00000526, and The Alfred Ethics Committee, Project 80/13. Ect cells were pretreated with pooled CVF diluted $1 / 3(\mathrm{w} / \mathrm{w})$ in SFKM for $4 \mathrm{~h}$, prior to removal by washing and subsequent stimulation with $0.3 \%$ L-LA (w/w) and/or PIC $\left(20 \mu \mathrm{g} \mathrm{ml}^{-1}\right)$ for $1 \mathrm{~h}$, and supernatants were collected after an additional $18 \mathrm{~h}$ for cytokine analysis. In other experiments, Ect cells were stimulated with $10 \%$ clarified human seminal plasma (Lee Biosolutions, St Louis, MO) in SFKM for 12-18 h in the absence or presence of $0.3 \% \mathrm{~L}-$ LA $(w / w)$, treatment media were removed and cells cultured for an additional $24 \mathrm{~h}$ to allow cytokine production. The production of IL-1RA, IL-1 $\beta$, IL-6, IL-8, TNF $\alpha$, RANTES, and MIP-3 $\alpha$ from stimulated epithelial cells was assessed using the ProcartaPlex Multiplex Immunoassay (Affymetrix, Santa Clara, CA). Samples were analyzed on a Bio-Plex 200 Luminex reader and analysis performed using the Bio-Plex Manager software (Bio-Rad, Hercules, CA).

Gene expression analysis. Ect cells $(300,000)$ cultured in $12 \mathrm{~mm}$ transwells were stimulated with PIC $\left(20 \mu \mathrm{g} \mathrm{ml}^{-1}\right)$ in the absence or 
presence of $0.3 \%$ L-LA ( $\mathrm{pH} 3.9$ ) or media adjusted to $\mathrm{pH} 3.9$ added to the apical chamber for $1 \mathrm{~h}$, the treatment media were removed, cells were washed then cultured for an additional $4 \mathrm{~h}$ in SFKM. Total cellular RNA was isolated using the RNeasy Mini (Qiagen, Hilden, Germany) kit following homogenization through a QIAShredder column (Qiagen), contaminating DNA removed by on column DNase digestion (Qiagen), and complementary DNA synthesized using the Transcriptor First Strand synthesis kit (Roche, Basel, Switzerland). Gene expression was assessed by quantitative PCR using the Brilliant II SYBR qPCR master mix (Agilent Technologies, Santa Clara, CA) containing $0.3 \mu \mathrm{M}$ of each primer. The following primer pairs were used to detect mRNA for Tnf (Fwd 5'-CCCCAGGGACCTC TCTCTAATC-3', Rev 5'-GGTTTGCTACAACATGGGCTACA-3'), Il-6 (5'-CAATCTGGATTCAATGAGGAGAC-3', Rev 5' -CTCTGG CTTGTTCCTCACTACTC-3'), Rantes (Fwd $5^{\prime}$-ATGGGTTCGGGA GTACATCA- $3^{\prime}$, and Rev 5'-GCAAGCAGAAACAGGCAAAT- $3^{\prime}$ ), and gene expression was standardized against the housekeeping gene Gapdh (Fwd 5'-TGGTATCGTGGAAGGACTCATGAC-3' and Rev $5^{\prime}$-ATGCCAGTGAGCTTCCCGTTCAGC- $3^{\prime}$ ). The effect of treatments on gene expression was assessed by comparison with untreated cells using the $\Delta \Delta \mathrm{C}_{\mathrm{T}}$ method. $^{52}$

Culture and treatment of organotypic EpiVaginal tissue model. Full-thickness EpiVaginal tissues, derived from primary human vaginal/ ectocervical cells and fibroblasts as previously described, ${ }^{32}$ were purchased from MatTek. Fully differentiated tissues were cultured in serum-free VEC-100 medium on cell culture inserts in 24-well plates. Each culture was confirmed to be confluent and span the entire insert using TEER measurements (TEER $>300 \Omega \mathrm{cm}^{2}$ ) prior to use in experiments and following treatment. Tissue viability following treatment was assessed using 3-[4, 5-dimethylthiazolyl-2]-2, 5diphenyltetrazolium bromide cell proliferation assay (American Type Culture Collection). For treatments, $50 \mu \mathrm{l}$ of $0.5-2 \%$ L-LA (adjusted to $\mathrm{pH}$ 3.9) and/or $10 \mathrm{ng} \mathrm{ml}^{-1}$ TNF (InvivoGen) in VEC-100 media were added to the apical chamber and $500 \mu \mathrm{l}$ of media alone were added to the basolateral chamber. Following $3 \mathrm{~h}$ of treatment, both chambers were washed with media, and then $500 \mu \mathrm{l}$ of fresh media alone was added to the basal compartment and tissues were incubated for $18 \mathrm{~h}$ to allow cytokine/chemokine production. Immune factors released into the apical compartment were collected by the addition of $500 \mu \mathrm{l}$ of media and analyzed using the ProcartaPlex Immunoassay (Affymetrix).

SUPPLEMENTARY MATERIAL is linked to the online version of the paper at http://www.nature.com/mi

\section{ACKNOWLEDGMENTS}

This work was supported by the National Health and Medical Research Council of Australia (NHMRC; Project Grant 1088564). G.T. was supported by the NHMRC Senior Research Fellowship (Grants 543105 and 1117748). L.B. was funded by the Fogerty International Center/NIH D43 grant. We wish to thank Dr Thomas Moench for critical review of the manuscript and gratefully acknowledge the contribution to this work of the Victorian Operational Infrastructure Support Program received by the Burnet Institute.

\section{AUTHOR CONTRIBUTIONS}

A.C.H., R.G., D.J.A., R.A.C., and G.T. designed the research; A.C.H., D.T., D.S., L.B., D.J.D.D., and M.A. performed research; A.C.H., D.T., D.S., M.A., L.B., D.J.D.D., D.J.A., R.G., and G.T. analyzed the data; and A.C.H. and G.T. wrote the paper.

\section{DISCLOSURE}

A.C.H. and G.T. are co-inventors on patent applications on the antiinflammatory effects of $L A$ on cervicovaginal epithelium (Patent Application AU201501042 and US Patent Application 20150306053). The remaining authors declare no conflict of interest.

Official journal of the Society for Mucosal Immunology

\section{REFERENCES}

1. UNAIDS. The Gap report (2014). http://files.unaids.org/en/media/unaids/ contentassets/documents/unaidspublication/2014/UNAIDS_Gap_report_ en.pdf.

2. Abdool Karim, Q., Sibeko, S. \& Baxter, C. Preventing HIV infection in women: a global health imperative. Clin. Infect. Dis. 50 (Suppl 3), S122-S129 (2010).

3. Aldunate, M. et al. Antimicrobial and immune modulatory effects of lactic acid and short chain fatty acids produced by vaginal microbiota associated with eubiosis and bacterial vaginosis. Front. Physiol. 6, 164 (2015).

4. Ravel, J. et al. Vaginal microbiome of reproductive-age women. Proc. Natl Acad. Sci. USA 108 (Suppl 1), 4680-4687 (2011).

5. Martin, H.L. et al. Vaginal lactobacilli, microbial flora, and risk of human immunodeficiency virus type 1 and sexually transmitted disease acquisition. J. Infect. Dis. 180, 1863-1868 (1999).

6. Borgdorff, $\mathrm{H}$. et al. Lactobacillus-dominated cervicovaginal microbiota associated with reduced HIV/STI prevalence and genital HIV viral load in African women. ISME J. 8, 1781-1793 (2014).

7. Taha, T.E. et al. Bacterial vaginosis and disturbances of vaginal flora: association with increased acquisition of HIV. AIDS 12, 16991706 (1998).

8. Sha, B.E. et al. Female genital-tract HIV load correlates inversely with Lactobacillus species but positively with bacterial vaginosis and Mycoplasma hominis. J Infect Dis 191, 25-32 (2005).

9. Cohen, C.R. et al. Bacterial vaginosis associated with increased risk of female-to-male HIV-1 transmission: a prospective cohort analysis among African couples. PLoS Med. 9, e1001251 (2012).

10. Anahtar, M.N. et al. Cervicovaginal bacteria are a major modulator of host inflammatory responses in the female genital tract. Immunity 42, 965-976 (2015).

11. Borgdorff, H. et al. Cervicovaginal microbiome dysbiosis is associated with proteome changes related to alterations of the cervicovaginal mucosal barrier. Mucosal Immunol. 9, 621-633 (2016).

12. Masson, L. et al. Defining genital tract cytokine signatures of sexually transmitted infections and bacterial vaginosis in women at high risk of HIV infection: a cross-sectional study. Sex Transm. Infect. 90, 580-587 (2014).

13. Gosmann, C. et al. Lactobacillus-deficient cervicovaginal bacterial communities are associated with increased HIV acquisition in young South African women. Immunity 46, 29-37 (2017).

14. Masson, L. et al. Genital inflammation and the risk of HIV acquisition in women. Clin. Infect. Dis. 61, 260-269 (2015).

15. Freeman, E.E., Weiss, H.A., Glynn, J.R., Cross, P.L., Whitworth, J.A. \& Hayes, R.J. Herpes simplex virus 2 infection increases HIV acquisition in men and women: systematic review and meta-analysis of longitudinal studies. AIDS 20, 73-83 (2006).

16. Passmore, J.S., Jaspan, H.B. \& Masson, L. Genital inflammation, immune activation and risk of sexual HIV acquisition. Curr. Opin. HIV AIDS 11, 156-162 (2016).

17. Arnold, K.B. et al. Increased levels of inflammatory cytokines in the female reproductive tract are associated with altered expression of proteases, mucosal barrier proteins, and an influx of HIV-susceptible target cells. Mucosal Immunol. 9, 194-205 (2016).

18. Ferreira, V.H. et al. Endometrial epithelial cell responses to coinfecting viral and bacterial pathogens in the genital tract can activate the HIV- 1 LTR in an NF\{kappa\}B-and AP-1-dependent manner. J. Infect. Dis. 204, 299-308 (2011).

19. Li, Q. et al. Glycerol monolaurate prevents mucosal SIV transmission. Nature 458, 1034-1038 (2009).

20. Herbst-Kralovetz, M.M. et al. Quantification and comparison of toll-like receptor expression and responsiveness in primary and immortalized human female lower genital tract epithelia. Am. J. Reprod. Immunol. 59, 212-224 (2008).

21. Doerflinger, S.Y., Throop, A.L. \& Herbst-Kralovetz, M.M. Bacteria in the vaginal microbiome alter the innate immune response and barrier properties of the human vaginal epithelia in a species-specific manner. J. Infect. Dis. 209, 1989-1999 (2014).

22. Pyles, R.B. et al. Cultivated vaginal microbiomes alter HIV-1 infection and antiretroviral efficacy in colonized epithelial multilayer cultures. PLOS ONE 9, e93419 (2014). 
23. Rose, W.A. 2nd, McGowin, C.L., Spagnuolo, R.A., Eaves-Pyles, T.D., Popov, V.L. \& Pyles, R.B. Commensal bacteria modulate innate immune responses of vaginal epithelial cell multilayer cultures. PLoS ONE7, e32728 (2012).

24. O'Hanlon, D.E., Moench, T.R. \& Cone, R.A. In vaginal fluid, bacteria associated with bacterial vaginosis can be suppressed with lactic acid but not hydrogen peroxide. BMC Infect. Dis. 11, 200 (2011).

25. Aldunate, $M$. et al. Vaginal concentrations of lactic acid potently inactivate HIV. J. Antimicrob. Chemother. 68, 2015-2025 (2013).

26. O'Hanlon, D.E., Moench, T.R. \& Cone, R.A. Vaginal pH and microbicidal lactic acid when lactobacilli dominate the microbiota. PLoS ONE 8, e80074 (2013).

27. Anderson, D.J., Marathe, J. \& Pudney, J. The structure of the human vaginal stratum corneum and its role in immune defense. Am. J. Reprod. Immunol. 71, 618-623 (2014).

28. Yazdi, A.S. \& Ghoreschi, K. The interleukin-1 family. Adv. Exp. Med. Biol. 941, 21-29 (2016).

29. Granowitz, E.V., Clark, B.D., Vannier, E., Callahan, M.V. \& Dinarello, C.A. Effect of interleukin-1 (IL-1) blockade on cytokine synthesis: I. IL-1 receptor antagonist inhibits IL-1-induced cytokine synthesis and blocks the binding of IL-1 to its type II receptor on human monocytes. Blood 79, 2356-2363 (1992).

30. Nazli, A. et al. HIV-1 gp120 induces TLR2- and TLR4-mediated innate immune activation in human female genital epithelium. J. Immunol. 191, 4246-4258 (2013).

31. Boskey, E.R., Cone, R.A., Whaley, K.J. \& Moench, T.R. Origins of vaginal acidity: high $\mathrm{D} / \mathrm{L}$ lactate ratio is consistent with bacteria being the primary source. Hum. Reprod. 16, 1809-1813 (2001).

32. Ayehunie, S. et al. Organotypic human vaginal-ectocervical tissue model for irritation studies of spermicides, microbicides, and feminine-care products. Toxicol. In Vitro 20, 689-698 (2006).

33. Robertson, S.A. Seminal plasma and male factor signalling in the female reproductive tract. Cell Tissue Res. 322, 43-52 (2005).

34. Sharkey, D.J., Macpherson, A.M., Tremellen, K.P. \& Robertson, S.A. Seminal plasma differentially regulates inflammatory cytokine gene expression in human cervical and vaginal epithelial cells. Mol. Hum. Reprod. 13, 491-501 (2007).

35. Mossop, H., Linhares, I.M., Bongiovanni, A.M., Ledger, W.J. \& Witkin, S.S. Influence of lactic acid on endogenous and viral RNA-induced immune mediator production by vaginal epithelial cells. Obstet. Gynecol. 118, 840846 (2011).

36. Witkin, S.S., Mendes-Soares, H., Linhares, I.M., Jayaram, A., Ledger, W.J. \& Forney, L.J. Influence of vaginal bacteria and D- and L-lactic acid isomers on vaginal extracellular matrix metalloproteinase inducer: implications for protection against upper genital tract infections. MBio 4, e00460-e00513 (2013).

37. Menard, S., Candalh, C., Bambou, J.C., Terpend, K., Cerf-Bensussan, N. \& Heyman, M. Lactic acid bacteria secrete metabolites retaining anti-inflammatory properties after intestinal transport. Gut 53, 821-828 (2004).

38. Lee, J.M., Hwang, K.T., Jun, W.J., Park, C.S. \& Lee, M.Y. Antiinflammatory effect of lactic acid bacteria: inhibition of cyclooxygenase-2 by suppressing nuclear factor-kappaB in Raw264.7 macrophage cells. J. Microbiol. Biotechnol. 18, 1683-1688 (2008).

39. Peter, K., Rehli, M., Singer, K., Renner-Sattler, K. \& Kreutz, M. Lactic acid delays the inflammatory response of human monocytes. Biochem. Biophys. Res. Commun. 457, 412-418 (2015).
40. Prakash, M., Patterson, S., Gotch, F. \& Kapembwa, M.S. Recruitment of CD4 T lymphocytes and macrophages into the cervical epithelium of women after coitus. Am. J. Obstet. Gynecol. 188, 376-381 (2003).

41. Verstraelen, H., Vervaet, C. \& Remon, J.P. Rationale and safety assessment of a novel intravaginal drug-delivery system with sustained DL-Lactic acid release, intended for long-term protection of the vaginal microbiome. PLOS ONE 11, e0153441 (2016).

42. Hemmerling, A. et al. Phase 2a study assessing colonization efficiency, safety, and acceptability of Lactobacillus crispatus CTV-05 in women with bacterial vaginosis. Sex Transm. Dis. 37, 745-750 (2010).

43. Larsson, P.G., Stray-Pedersen, B., Ryttig, K.R. \& Larsen, S. Human lactobacilli as supplementation of clindamycin to patients with bacterial vaginosis reduce the recurrence rate; a 6-month, double-blind, randomized, placebo-controlled study. BMC Womens Health 8, 3 (2008).

44. Keller, M.J. et al. Phase I randomized safety study of twice daily dosing of acidform vaginal gel: candidate antimicrobial contraceptive. PLOS ONE 7, e46901 (2012).

45. Abdool Karim, Q. et al. Effectiveness and safety of tenofovir gel, an antiretroviral microbicide, for the prevention of HIV infection in women. Science 329, 1168-1174 (2010).

46. Naranbhai, V. et al. Innate immune activation enhances hiv acquisition in women, diminishing the effectiveness of tenofovir microbicide gel. J. Infect. Dis. 206, 993-1001 (2012).

47. Biswas, N. et al. Effects of tenofovir on cytokines and nucleotidases in HIV-1 target cells and the mucosal tissue environment in the female reproductive tract. Antimicrob. Agents Chemother. 58, 6444-6453 (2014).

48. Baeten, J.M. et al. A Phase III Trial of the Dapivirine Vaginal Ring for HIV-1 Prevention in Women. 23rd Conference on Retroviruses and Opportunistic Infections, Boston, Massachusetts, USA (2016).

49. Fichorova, R.N., Rheinwald, J.G. \& Anderson, D.J. Generation of papillomavirus-immortalized cell lines from normal human ectocervical, endocervical, and vaginal epithelium that maintain expression of tissuespecific differentiation proteins. Biol. Reprod. 57, 847-855 (1997).

50. Tyssen, D. et al. Structure activity relationship of dendrimer microbicides with dual action antiviral activity. PLOS ONE 5, e12309 (2010).

51. Price, C.F. et al. SPL7013 Gel (VivaGel(R)) retains potent HIV-1 and HSV-2 inhibitory activity following vaginal administration in humans. PLOS ONE 6, e24095 (2011).

52. Livak, K.J. \& Schmittgen, T.D. Analysis of relative gene expression data using real-time quantitative PCR and the 2(-Delta Delta $C(T))$ method. Methods 25, 402-408 (2001).

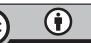

This work is licensed under a Creative Commons Attribution 4.0 International License. Theimages or other third partymaterialin this articleareincluded in thearticle's Creative Commons license, unless indicated otherwise in the credit line; if the material is not included under the Creative Commons license, users will need to obtain permission from the license holder to reproduce the material. To view a copy of this license, visit http://creativecommons.org/licenses/by/4.0/

(C) The Author(s) 2017 